\title{
Health-care expenditures, economic growth and infant mortality: evidence from developed and developing countries
}

\author{
Abdelhafidh Dhrifi
}

\section{Abstract}

This paper investigates the effects of health-care expenditures on child mortality rates using a simultaneous-equation model for 93 developed and developing countries with data spanning the period 1995-2012. The findings show that health expenditure has a positive effect on reducing child mortality only for upper-middle-income and high-income countries, whereas for low-income and lower-middle-income countries, health spending does not have a significant impact on child health status. It is also found that at lower development levels, public health spending has a greater effect on mortality rates than private expenditure, while at high development levels private health expenditure has a positive impact on child mortality.

\section{Keywords}

Health, health economics, infant mortality, statistical data, econometric models, developed countries, developing countries

\section{JEL classification}

$\mathrm{H} 51, \mathrm{O} 47, \mathrm{I12}$

\section{Author}

Abdelhafidh Dhrifi is Doctor of Economics at the Faculty of Economics and Management of the University of Sousse, Tunisia. Email: abdelhafidh.dhrifi@gmail.com. 


\section{Introduction}

Child mortality is a very worrying demographic phenomenon especially in developing countries, which has attracted the attention of various stakeholders including researchers and policymakers. Today, combating this scourge is considered a key policy objective and strategy. At the same time, international organizations, such as the United Nations Children's Fund (UNICEF), the World Bank and the World Health Organization (WHO) have incorporated the objective of reducing child mortality into most of their future programmes.

According to UNICEF, ${ }^{1}$ about 29,000 children under the age of five die every day, in other words an average of 21 per minute, mainly from preventable causes. Most of these deaths occur in developing countries. For example, an Ethiopian child is 30 times more likely to die before his or her fifth birthday than a child in Western Europe. Some deaths are the result of diseases such as measles, malaria or tetanus. While malnutrition and the lack of safe drinking water and sanitation are a factor in half of all child deaths. Research and experience show that of the almost 11 million children who die every year, 6 million could be saved by simple measures, such as vaccines, antibiotics, insecticide-treated bed nets, micronutrient supplements, improved family care and breastfeeding. For that reason, reducing the burden of mortality and morbidity among the poor is widely regarded as one of the foremost public health challenges in the world today and has become a major concern of the international community, as was reflected in the Millennium Development Goals ${ }^{2}$ and now in the Sustainable Development Goals of the 2030 Agenda for Sustainable Development. $^{3}$

The role of health economics today is crucial because of growing international awareness of the close relationship between economic development and health. Furthermore, as health in childhood is one of the key predictors of health and productivity in later life, child mortality is an important indicator of socioeconomic development. Research of the factors underlying high child mortality around the world has found several upstream factors, including the residential environment, economic region and the parents' level of education. At the same time, countries have prioritized policies on health-care expenditure in view of the fact that countries with high levels of health spending are those that have succeeded in lowering their mortality rates.

The above provides a backdrop to this study which, unlike the traditional approach that tests only the direct effects of health expenditures on child mortality, aims to test both the direct impact of health-care expenditures - in terms of making it possible to satisfy medical needs -and the indirect effect as evidenced by economic growth. The paper also attempts to break health expenditure down into its private and public components to study their effects on child mortality rates.

Studying this relationship is important because it will afford a better understanding of the effectiveness of health expenditures on childhood health. Analysis of the relationship between healthcare expenditures, economic growth and child mortality can address the issue of health status most thoroughly. Thus, the real challenge in designing a child-mortality reduction policy is to understand these interactions.

This paper analyses the tripartite relationship among developed and developing economies, by comparing low, lower-middle, upper-middle and high-income countries. It uses aggregate annual panel data, obtained from WHO and World Development Indicators on health-care expenditure and

1 See United Nations Children's Fund (UNICEF), "Goal: Reduce child mortality" [online] https://www.unicef.org/mdg/ childmortality.html.

2 Millennium Development Goal 4 proposed to reduce the under-five mortality rate by two thirds, from 93 deaths per 1,000 live births in 1990 to 31 per 1,000 live births by 2015 .

3 Sustainable Development Goal target 3.2: By 2030, end preventable deaths of newborns and children under 5 years of age, with all countries aiming to reduce neonatal mortality to at least as low as 12 per 1,000 live births and under-5 mortality to at least as low as 25 per 1,000 live births. 
child mortality rates, for a sample of 93 developed and developing countries, with data spanning 1995 to 2013, to estimate a model of the interrelationships between the health system and the under-fives mortality rate. Following this introduction, the remainder of the paper is organized as follows: section II provides an overview of the relationship between health-care expenditures and child mortality. Section III presents stylized facts on the causes of child mortality. The following section contains an outline of the model, data descriptions and validation. Section $V$ contains a robustness analysis and a discussion of results, and the paper concludes and presents policy implications in section VI.

\section{Literature review}

This section surveys the related empirical studies in the field of health economics, presenting the main results obtained on the interactions between health-care expenditure, economic growth and child mortality. Some of these studies have shown that health expenditures have no impact on health-care production. Others report a positive impact, and a third group finds the impact to be ambiguous.

\section{No health-expenditure effect on child mortality}

Musgrove (1996) and Filmer and Pritchett (1997) provide evidence that public spending on health is not a factor in reducing child mortality. These authors believe that variables such as income, income inequality, women's education and degree of ethno-linguistic fragmentation explain nearly all the variation in child mortality rates. Based on these results, they argue that, rather than increasing public health expenditure, policies that encourage economic growth, reduce poverty and income inequality, and increase the level of women's education should be supported to reduce child mortality. Wagstaff, Van Doorslaer and Watanabe (2003) show that the development of good policy and the quality of institutions are important determinants of the impact of public-health expenditure on the production sector. Roberts and Bogg (2004) show that children born into lowincome households are more likely to experience developmental and health problems from birth and to accumulate health risks as they grow older. Although many researchers have highlighted the links between poverty and mortality, it is important to recognize that this relationship runs in both directions: as Wagstaff (2002) notes, "poverty breeds ill-health, and ill-health keeps poor people poor". It is also important to be aware of socioeconomic differences in access to health services. There is much evidence that, relative to needs, people in lower socioeconomic groups are less likely to use health services than their higher-income counterparts, and they are more likely to delay seeking treatment.

\section{Health expenditure and child mortality: both positive and negative relationships}

Some studies over the past decade have shown a positive relationship between health spending and health capital (Baldacci and others, 2004). Others reported the opposite (Filmer and Pritchett, 1999), and some, such as Baldacci, Guin-Siu and de Mello (2003) found that the results depended on the types of data and estimation methods used. A final category showed that contribution of health spending to the population's health status, as measured by child mortality and maternal mortality, is even less statistically significant (Filmer, Hammer and Pritchett, 1998; Musgrove, 1996). 
Using data from 50 developing and transition countries, Gupta and Baghel (1999) found that health spending reduces child mortality rates. By using specific data on health-care spending in 20 countries of the Organization for Economic Cooperation and Development (OECD) over the period 1960-1992, Berger and Messer (2002) found that mortality rates depend simultaneously on health spending and the type of health insurance coverage. More specifically, an increase in the share of public expenditure allocated to health spending has been associated with a reduction in mortality rates.

Khaleghian and Das Gupta (2005), in a study of over 70 developing and transition economies, show that public health expenditure plays a more important role for the poor in low-income countries than in high-income ones, while also noting that the returns on health expenditure are higher in low-income countries. Harttgen and Misselhorn (2006) show that access to health-care infrastructure significantly reduces child mortality and that socioeconomic factors are the main determinants of child health status (Nolte and McKee, 2004).

Baldacci, Guin-Siu and de Mello (2003) and Gupta, Verhoeven and Tiongson (2002) found that social spending plays a significant role in the health and education sectors. These studies also show that spending on education has more effect on human development indicators than health spending. This positive relationship between social spending and human development indicators was also corroborated by a study by Ravallion (1997). These authors show that public health expenditures have a positive impact on the health status of low-income groups. Bokhari, Gay and Gottret (2007) also show that, while economic growth is one of the main determinants of health outcomes in developing countries, government spending on health is also an important factor. Lastly, using Demographic and Health Survey data, Wang and Wang (2002) review the determinants of health outcomes in low-income countries both at the national level and in rural and urban areas. They note that public health expenditure at the national level can reduce child mortality significantly.

Nixon and Ulmann (2006) find that increases in health-care expenditure has made a relatively marginal contribution to higher life expectancy in 15 European Union countries over a period of analysis spanning 1980-1995. Also, in cross-sectional data covering 117 countries for 1993, Zakir and Wunnava (1997) find that government spending on health care, as a percentage of gross national product (GNP), does not play a major role in determining child mortality rates.

The divergences in findings suggest that it would be worthwhile to clarify these relationships in the 93 developed and developing countries of the sample. Using simultaneous-equation models, which have not been used in other studies on this subject, has the advantage of decoupling the direct effects of better quality health-care infrastructure from the indirect effects of economic growth.

\section{Stylized facts and causes of child mortality}

According to the Inter-Agency Group for Child Mortality Estimation (2015), the under-five mortality rate decreased by 53\%, from 91 deaths per 1,000 live births in 1990 to 43 per 1,000 live births in 2015 . Globally, the average annual rate of reduction in the under-five mortality rate rose from 1.8\% in 1990-2000 to 3.9\% for 2000-2015, although this was insufficient to attain Millennium Development Goal 4, which required an annual decline of 4.3\% over the entire period. Nevertheless, about 19,000 fewer children died per day in 2015 than in 1990 and, among the developing regions, Northern Africa, Eastern Asia and Latin America and the Caribbean all attained the MDG target of reducing the under-five mortality rate by two thirds or more (see figures 1 and 2). ${ }^{4}$ Yet, even in those regions, many countries missed the target, despite improving the pace of reduction in the under-five mortality rate.

\footnotetext{
4 The figures in this paper were prepared by the author, on the basis of data from the World Bank and the World Development Indicators.
} 
Figure 1

Global child mortality rate and global health expenditure, 1995-2012

(Rate per 1,000 live births and trillions of dollars)

\section{A. Global health expenditure}

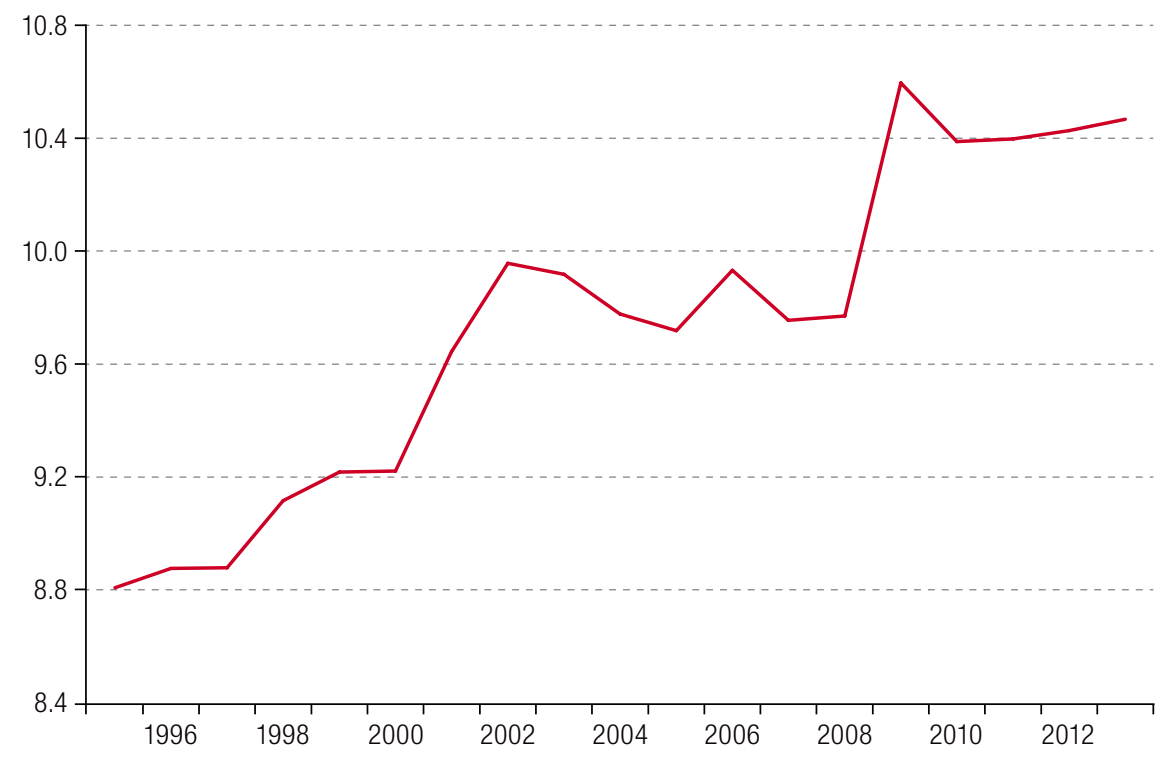

B. Global child mortality

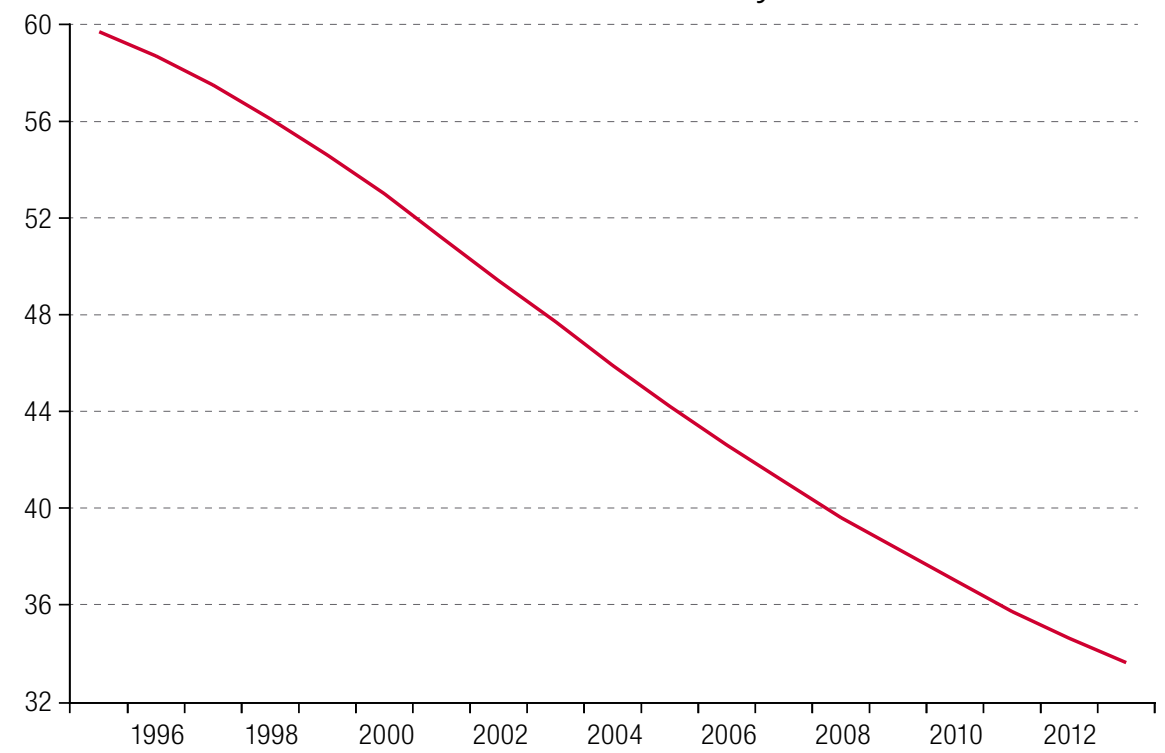

Source: Prepared by the author.

The ratio between the 10 highest national child mortality rates and the 10 lowest is 38 . For example, an Afghan child in 2015 was 35 times more likely to die before his or her first birthday than a French child. Recent estimates suggest that nearly $80 \%$ of global deaths among children aged under five occur in sub-Saharan Africa and southern Asia; and in 2008 nearly half occurred in five countries: India, Nigeria, the Democratic Republic of the Congo, Pakistan and China (Black and others, 2010). India and Nigeria together accounted for more than a third of under-five deaths in 2013. The fact that a large proportion of child deaths are caused by preventable and treatable infectious diseases is symptomatic of dysfunctional health systems in the developing world. For example, newborns accounted for nearly half (44\%) of global under-five deaths. This may be because many sub-Saharan African countries have 
major deficits in terms of access to basic social services, including education and health services; clean drinking water; adequate nutrition; and hygiene and sanitation services. Thus, life expectancy at birth is among the lowest in the world (see table 1 and figure 3), while the child mortality rate decreased by 21 percentage points, from 168 deaths per 1,000 live births in 1990 to 126 per 1,000 in 2013. However, progress was insufficient to achieve the target set under MDG 4 across the continent.

Figure 2

Child mortality by region

(Rate per 1,000 live births)

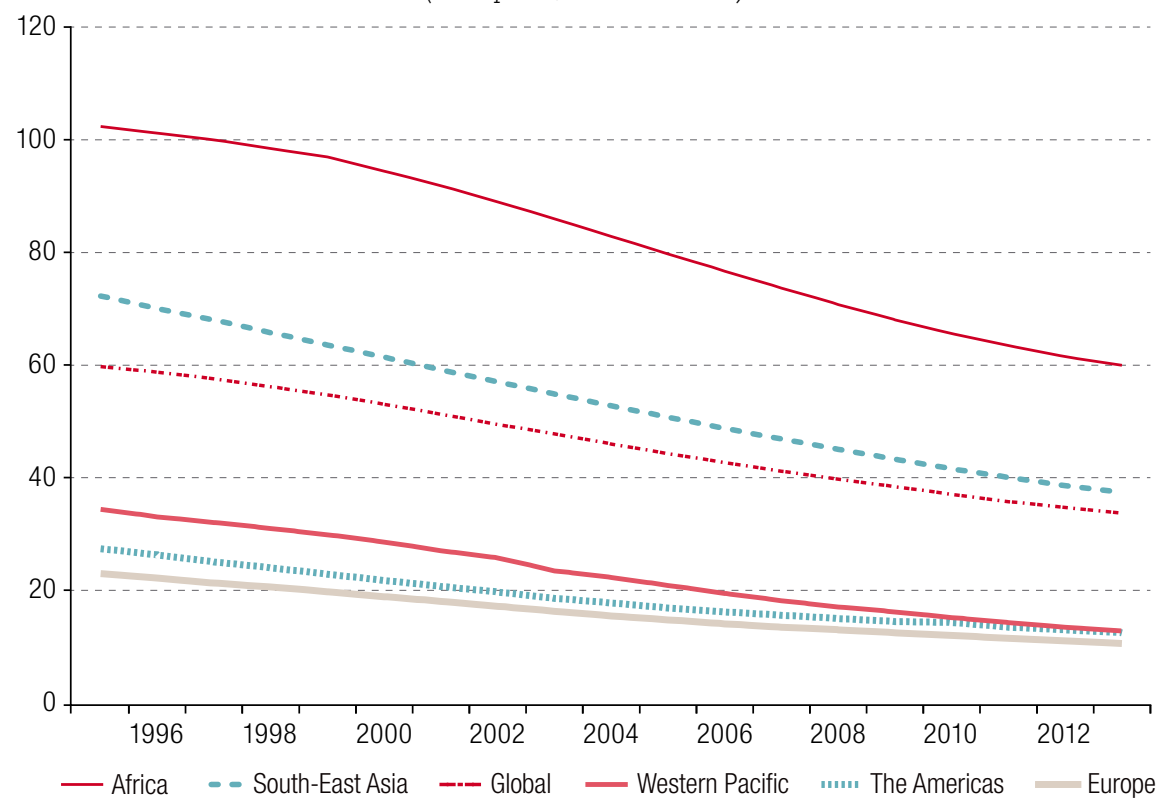

Source: Prepared by the author.

Figure 3

Average child mortality and life expectancy at birth in the sample countries (Rate per thousand live births and years) ${ }^{\mathrm{a}}$

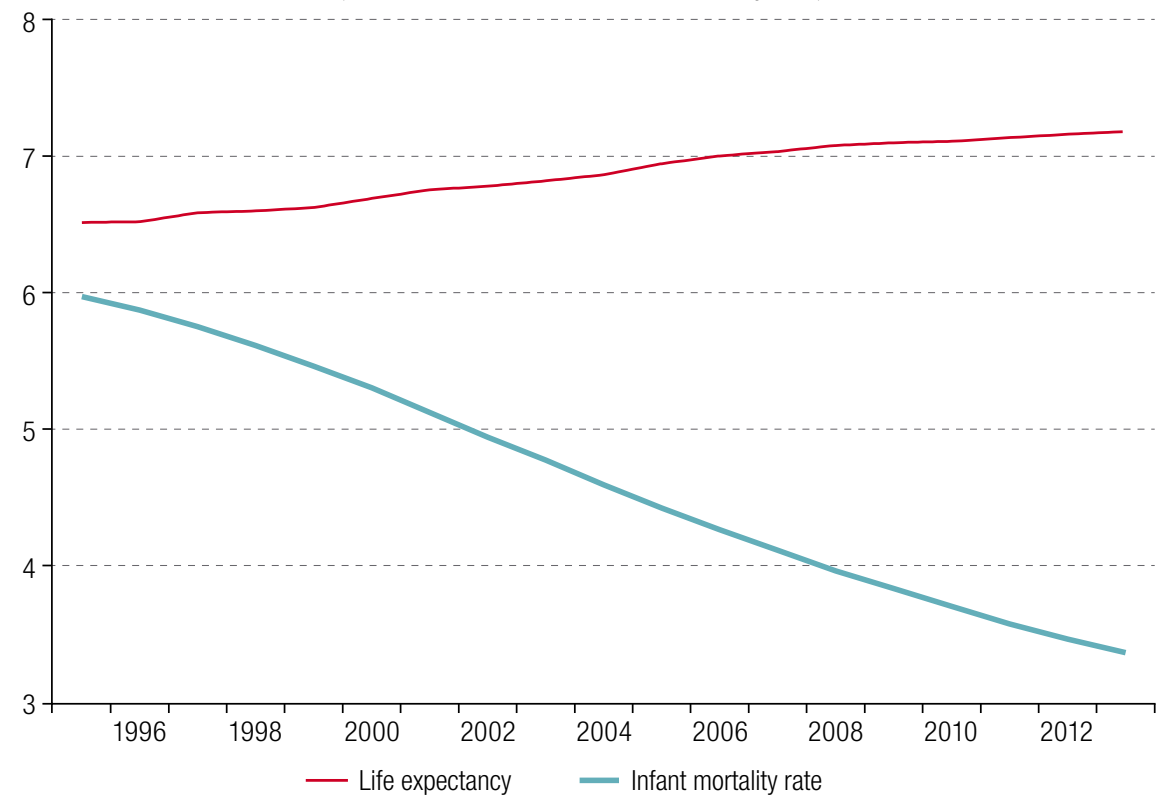

Source: Prepared by the author.

a Both measures are given by the left scale. 
Table 1

Life expectancy at birth by region

(Years)

\begin{tabular}{lcccc}
\hline & 1990 & 2000 & 2012 & 2013 \\
\hline Africa region & 50 & 50 & 58 & 58 \\
\hline Region of the Americas & 71 & 74 & 76 & 77 \\
\hline South-East Asia region & 59 & 63 & 67 & 68 \\
\hline European region & 72 & 72 & 76 & 76 \\
\hline Eastern Mediterranean region & 62 & 65 & 68 & 68 \\
\hline Western Pacific region & 69 & 66 & 76 & 76 \\
\hline Global & 64 & & 70 & 71 \\
\hline
\end{tabular}

Source:World Health Organization (WHO), World Health Statistics, 2015, Luxembourg, 2015.

Furthermore, some $45 \%$ of all under-five deaths are linked to malnutrition among the under-fives; and a child who is exclusively breastfed is 14 times less likely to die in the first six months of life than a non-breastfed child. Countries needed to intensify their efforts to establish a credible vital registration system to improve the quality of health information available and enhance their ability to monitor progress towards Sustainable Development Goal target 3.2. At the micro level, many countries are locked in a poverty trap, which contributes significantly to their poor health status. As a result, equity must be considered in public health policies, which are currently relatively unfavourable to the poor. In high-income countries, per capita health expenditure was over US $\$ 3,000$ on average in 2008, compared to just US\$ 30 per capita in resource-poor countries. According to the World Bank, in 2013, over 50 countries spent less than US\$100 per capita on health. There is also wide variation in health expenditure relative to economic development. Some countries spend more than $12 \%$ of their gross domestic product (GDP) on health, while others spend less than 3\% (see figures 4 and 5).

Figure 4

Health-care expenditure by region

(Billions of dollars)

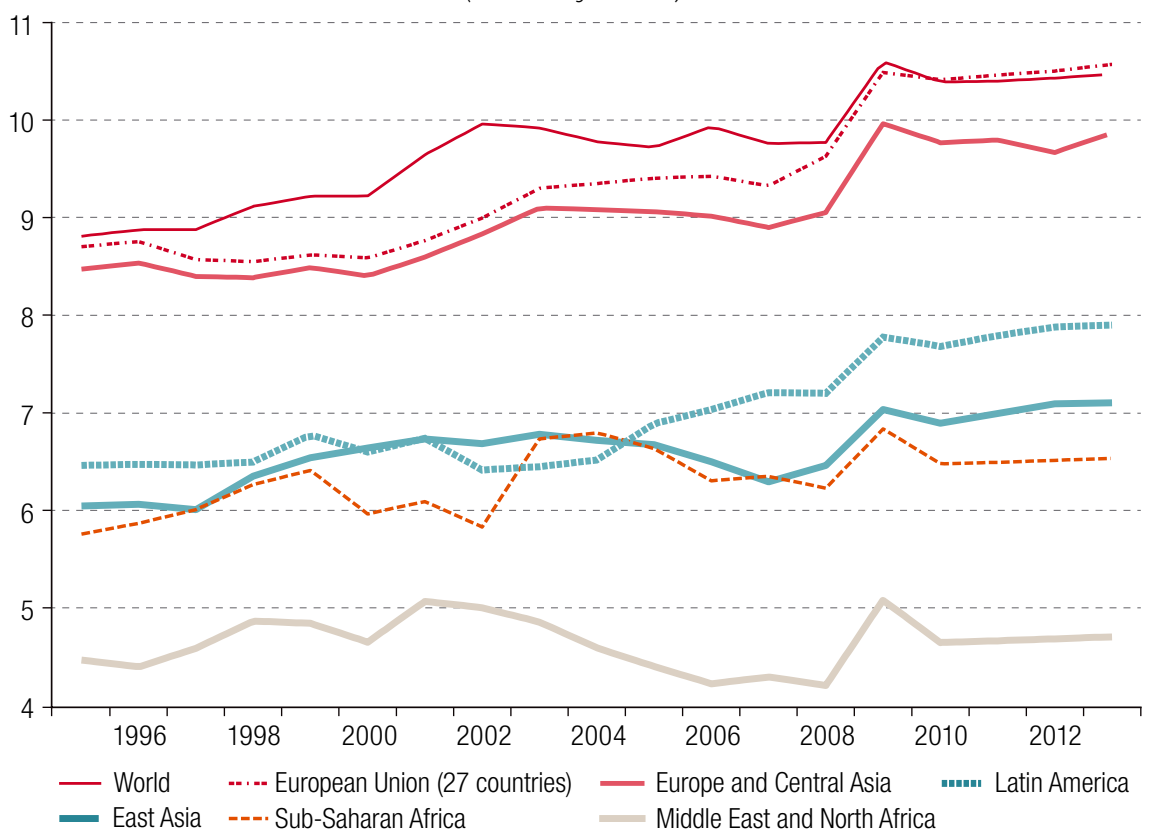

Source: Prepared by the author. 
Figure 5

Health-care expenditure by countries' income level classification

(Billions of dollars)

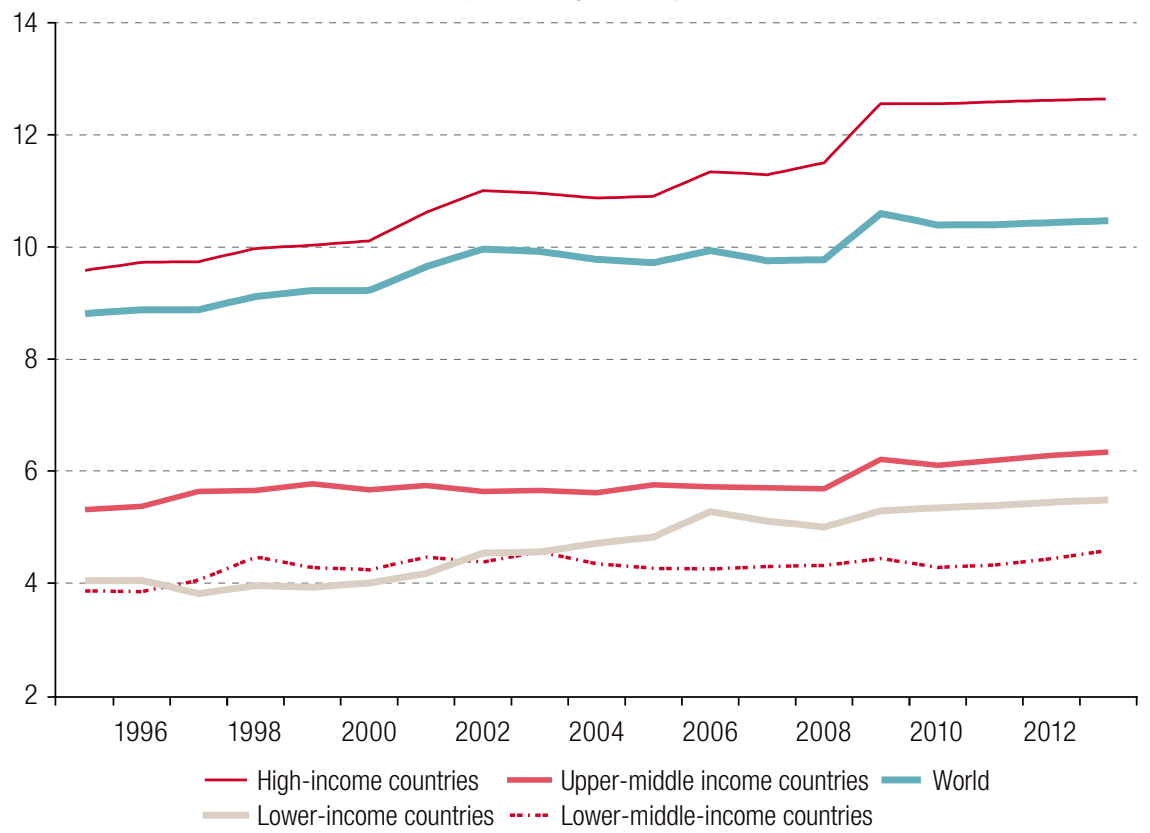

Source: Prepared by the author.

\section{Empirical model specification and data description}

\section{The econometric modelling}

The objective of this paper is to analyse the interrelationship between health expenditures, economic growth and child mortality, in 93 developed and developing countries using annual data spanning 1995-2013. The sample was chosen on the basis of two criteria: first, the availability of data for the variables used in the model; and second, heterogeneity to test whether the effects of health spending are the same in both developed and developing countries.

The three variables in question are actually endogenous. As noted above, most of the literature generally assumes that health expenditures foster economic growth; but it has also been established that economic growth is often a key determinant of child mortality. So, it is worth investigating the interrelationships between the three variables by considering them simultaneously in a modelling framework.

To empirically investigate the impact of health spending on child mortality, a model needs to be specified that makes it possible to capture both the direct and the indirect effects. A simultaneous equations model is considered the most appropriate for this problem, because it can simultaneously test the effects of health expenditures on child mortality, both directly in terms of satisfying medical needs and indirectly via economic growth. The model's specification is consistent with those reported in the literature and makes it possible to identify the channels through which total health spending and other variables affect childhood health.

In analysing the effects of health expenditure on child mortality, while also considering the role of economic growth, the two explanatory variables (health expenditure and economic growth) must themselves be explained. An obvious reason for the endogeneity of these two explanatory variables in 
the regression model is simultaneity: in other words, at least one of the explanatory variables is jointly determined with the dependent variable. Models of this type are known as simultaneous equations models.

There are three equations to explain the whole phenomenon: a mortality equation, a growth equation and a health expenditure equation. It is not necessary in this case for all the variables to appear in all the equations, so parameter estimation has features not present in a model that involves only a single relationship. In particular, when a relation is a part of a system, some explanatory variables are stochastic and are correlated with the disturbances. Accordingly, the basic assumption of a linear regression model that the explanatory variable and disturbance terms are uncorrelated, or explanatory variables are fixed, is violated; and the ordinary least squares estimator becomes inconsistent. Just as the variables in a linear regression model are classified as explanatory and dependent, those in simultaneous equation models are classified as endogenous and exogenous.

This distinction is important because a necessary condition for uniquely estimating all the parameters is that the number of endogenous variables is equal to the number of independent equations in the system. Moreover, the distinguishing feature of predetermined variables in parameter estimation is that they are uncorrelated with the disturbance terms in the equations in which they appear.

This paper will simultaneously regress equations for child mortality (1), economic growth (2) and health expenditure (3). The first tests the direct effects, while the two others test the indirect ones. The first basic equation examines the direct impact of health spending on the child mortality rate, as proxied by the under-five mortality rate. In addition to health care expenditures, the specification of the child mortality equations includes seven other variables that are identified by the health economics literature as key determinants of health, namely poverty; per capita GDP growth; life expectancy; water use efficiency; the female literacy rate; urbanization; and $\mathrm{CO}_{2}$ emissions, which capture the cleanliness of the environment.

Following Barro (1996) and Ravallion (1997), a set of macroeconomic variables that are widely used as evidence of economic growth are modelled as a function of economic growth, in addition to the health expenditure variable. These are the Gini coefficient to test the effect of inequality; inflation; trade openness; financial development; the rate of investment; and the labour force. The health economics literature recognizes that the relationship between economic growth and health status is multifaceted and bidirectional.

Drawing on the existing literature on the determinants of health expenditure, the set of explanatory variables includes per capita income (GDP) which has been identified as a very important factor for explaining differences in the level and growth of total health expenditures between countries; and the population age structure (POPSTR), which is often included as a covariate in health expenditure regressions, such as the proportion of young (for example, those aged under 15) and older people (aged over 65 or 75 ) in the active or total population. These variables have traditionally been flagged as important factors in explaining variations in health expenditure. Physicians density, which is defined as the number of doctors per 1,000 inhabitants and is used to account for the supply of health care, can be considered a factor behind higher health spending. Technological progress (measured by research and development (R\&D)) and institutional quality (measured by the rule of law) are also factors determining health expenditure.

The complete model used in this study to estimate the impact of health expenditure (HEXP) on child mortality (CHM) can be expressed as follows:

$$
\begin{aligned}
& C H M_{i t}=\gamma_{0}+\gamma_{1} G D P G_{i t}+\gamma_{2} H E X P_{i t}+\gamma_{3} P O V_{i t}+\gamma_{4} W_{\text {WTRit }} \gamma_{5} L E X P_{i t} \\
& +\gamma_{6} \mathrm{FemL}_{i t}+\gamma_{7} \mathrm{Urb}_{i t}+\gamma_{8} \mathrm{CO} 2_{i t}+\xi_{1 i t} \\
& G D P G_{i t}=\alpha_{0}+\alpha_{1} I N Q_{i t}+\alpha_{2} \operatorname{Inf}_{i t}+\alpha_{3} T R A D E_{i t}+\alpha_{4} F D_{i t}+\alpha_{5} H E X P_{i t} \\
& +\alpha_{6} R I_{i t}+\alpha_{7} L F_{i t}+\xi_{2 i t} \\
& H E X P_{i t}=\beta_{0}+\beta_{1} \text { GDPG }_{i t}+\beta_{2} \text { TechProg }_{i t}+\beta_{3} \text { DocDens }_{i t}+\beta_{4} \text { Popstr }_{i t}+\beta_{5} I N S T_{i t}+\xi_{3 i t}
\end{aligned}
$$




\section{Data descriptions}

The model specification is consistent with the literature and makes it possible to identify the channels through which health expenditure and other policy interventions affect child mortality over time. The different variables listed above are defined as follows:

- Mortality rate (CHM): proxied by under-five mortality (per 1,000 live births): this measures the proportion of deaths among children under five years of age. It provides an indication of the impact of the socioeconomic situation of the mothers, their lifestyles and characteristics, and the effectiveness of health systems for maternal and newborn health.

- $\quad$ Health-care expenditures (HEXP): the variable used in this study as a proxy of health expenditure is total per capita health expenditure, including government and private spending. Countries that spend more on health care are likely to have a longer life expectancy and, consequently, a lower mortality rate. According to the health economics literature, an increase in health spending implies broader access to health-care and other services, which helps to reduce child mortality rates. Thus, improving the population's health status should foster economic growth and hence reduce poverty; and, given the negative relation that exists between poverty and mortality, this may reduce the child mortality rate. ${ }^{5}$

- Inequality (INQ): the Gini coefficient is the most widely used index of income inequality and can refer to either household or per capita income. It is expected to be positively correlated with the dependent variables, since greater income inequality within countries reflects unequal access to health care, nutrition and other services, which is likely to reduce mortality rates.

- $\quad$ Poverty (POV): per capita consumption is used as a proxy for poverty (Odhiambo, 2009; Dhrifi, 2014 and 2015). This is consistent with the definition proposed by the World Bank.

- $\quad$ GDP growth (GDPG): which represents per capita GDP growth. The advantage of this indicator is that World Bank data cover most countries over a long period of time.

- $\quad$ Female literacy (FemL): represents the female literacy rate, which is considered an important determinant of child health status, as well as that of the population at large (Baldacci, Guin-Siu and De Mello, 2003).

- Water access (Water): Access to drinking water is measured by the proportion of households that obtain water considered drinkable from a tap, or from protected wells and boreholes. The indicators consider access conditions, in this case the distance to the water source when the relevant information is available.

- $\quad$ Environmental degradation: measured by per capita $\mathrm{CO}_{2}$ emissions expressed in metric tons; captures the cleanliness of the environment.

- $\quad$ Life expectancy at birth: refers to the average number of years a newborn would be expected to live if mortality patterns at the time of birth were to remain constant in the future (World Bank).

- Labour force: measured by the number of people who are employed plus the unemployed who are seeking work.

- $\quad$ Urbanization (URB): urban population as a share of the total population proxies for urbanization; Roberts (2003) has emphasized that geographical and demographic factors such as rural or urban location, and the percentage of the population in those locations, affect health outcomes (Schultz, 1993; Baldacci and others, 2004).

- Inflation (INF): inflation is measured by growth of the consumer price index, for which the data are available from the World Bank. This is included in the model to capture the impact of macroeconomic stabilization on growth.

\footnotetext{
5 The Commission on Macroeconomics and Health of the WHO supports this view (WHO, 2001).
} 
- $\quad$ Trade (TRA): this variable represents trade openness and is defined as the sum of exports and imports relative to GDP. It is included in the model to capture the degree of international openness.

- $\quad$ Financial development (FD): this is measured by the ratio of private sector domestic credit relative to GDP. A positive and significant relationship is expected between the indicator of financial development and economic growth.

- $\quad$ Technological progress (TechProg): this is measured by R\&D expenditure (as a percentage of GDP). Scheffler and others (2009) noted that health-care costs are rising because of technology. In many industrialized countries, the enormous growth of health spending is indirectly linked to this factor.

- Investment rate (IR): this is measured by gross capital formation (as a percentage of GDP), which should have positive effects on economic growth.

- $\quad$ Population age structure (PopStr): the population age structure is often included as a covariate in health expenditure regressions. Commonly used indicators include the proportion of young people (aged under 15) in the active population.

- $\quad$ Physicians density (DocDens): this is the number of doctors per 1,000 inhabitants and is used to measure the availability of health care in a country. A larger number of doctors relative to the population indicates easier access to health care and should correlate with a lower mortality rate.

- Institutions (INST): this is an index reflecting the quality of institutions, as measured by law and order, also referred to as the rule of law. It is based on the International Country Risk Guide, which assesses the strength and impartiality of the legal system and popular observance of the law.

Lastly, this study uses annual time series data covering 1995-2013 for a sample of 93 developed and developing countries. The data are obtained from a variety of sources, including series compiled by $\mathrm{WHO}$ and the World Bank and the International Financial Statistics database of the International Monetary Fund (IMF). The sample size and the period of the study are limited by the availability of data for the control variables.

Summary descriptive statistics of the variables used in the empirical analyses are provided in table 2. Among the variables of interest, the child mortality rate in the sample averaged 42.5 per 1,000 live births, ranging from a minimum of 2.1 per 1,000 live births to a maximum of 192 per 1,000 births. In the case of per capita GDP growth, the average for countries in the sample was about $0.02 \%$ during the period considered, ranging from a high of $9.3 \%$ to a low of $-2 \%$. For the third variable of interest, health expenditure, countries spent between $3.8 \%$ and $12.3 \%$ of their GDP on health, the average being $7.8 \%$.

Table 2

Descriptive statistics

\begin{tabular}{lccccc}
\hline & Number of observations & Minimum & Maximum & Mean & Standard deviation \\
\hline CHM & 1767 & 2.10 & 192 & 42.500 & 6.452 \\
\hline GDPG & 1767 & -2.04 & 9.30 & 0.022 & 0.047 \\
\hline HEXP & 1767 & 0.00 & 0.28 & 0.142 & 0.022 \\
\hline Water & 1767 & 0.04 & 0.67 & 0.390 & 0.571 \\
\hline POV & 1767 & 0.13 & 1.38 & 0.676 & 0.147 \\
\hline Life expectancy & 1767 & 55.70 & 83.60 & 71.500 & 4.654 \\
\hline FemL & 1767 & 14.16 & 99.88 & 84.530 & 2.314 \\
\hline URB & 1767 & 1.87 & 100 & 53.850 & 1.089 \\
\hline CO & 1767 & 0.10 & 46.70 & 5.990 & 3.427 \\
\hline INQ & 1767 & 0.00 & 0.67 & 0.039 & 0.047 \\
\hline INF & 1767 & -0.91 & 8.99 & 1.625 & 3.874 \\
\hline TRA & 1767 & 0.00 & 2.21 & 0.735 & 0.334 \\
\hline FD & 1767 & 8.20 & 174.30 & 66.450 & 8.265 \\
\hline IR & 1767 & 0.62 & 2.63 & 1.055 & 0.153 \\
\hline Labour force & 1767 & 0.08 & 0.34 & 0.016 & 0.026 \\
\hline TechProg & 1767 & 0.00 & 4.04 & 0.374 & 0.456 \\
\hline
\end{tabular}


Table 2 (concluded)

\begin{tabular}{lccccc}
\hline & Number of observations & Minimum & Maximum & Mean & Standard deviation \\
\hline DocDens & 1767 & 0.03 & 1.00 & 0.590 & 0.293 \\
\hline PopStr & 1767 & 0.00 & 4.04 & 0.374 & 0.456 \\
\hline INST & 1767 & 0.00 & 1.00 & 0.550 & 0.012 \\
\hline
\end{tabular}

Source: Prepared by the author

\section{Estimation techniques}

Simultaneous equation models are normally used when the endogenous variable in one equation becomes an exogenous variable in another. Estimation methods that can be used in the context of simultaneous equation models depend on identification criteria ${ }^{6}$ for estimating the model and the endogeneity problem. In the present case, the model is overidentified, so using ordinary least squares (OLS) to estimate the structural equations will result in inconsistent estimates for the model parameters. The model therefore has an endogeneity problem of order two, which is why estimation by OLS would be double-registered. This estimation method is based on the three-stage least squares (3SLS) technique, which aims to solve endogeneity problems by introducing the problematic variables as instrumental variables. Treatment with STATA 13 gives a solution using the 3SLS method. ${ }^{7}$

\section{Main results and discussion}

Table 3 sets out the results of the estimation of the simultaneous equations model using the 3SLS method for 1995-2013. The first row shows the results for the child mortality equation, in which the parameters of interest are as follows: the coefficient that represents the effect of health-care expenditure and GDP growth on child mortality. The estimated coefficient on health expenditures which encompasses both private and public spending shows a clear positive relationship between health expenditure and child mortality. The $\gamma_{3}$ value for this model measures the elasticity of child mortality with respect to health expenditure. The coefficient of -0.17 indicates that a one-unit increase in health expenditure would result in a 0.17 unit reduction in child mortality, which suggests that an increase in health expenditure per capita implies wider access to health care and other services that help to reduce under-five mortality rates.

The results also demonstrate that per capita income growth has a significant effect on reducing child mortality: a $1 \%$ increase in per capita income reduces child mortality by 0.76 of a percentage point. Low under-five mortality rates seem to suggest that economic growth leads to lower child mortality. A high growth rate would be expected to solve problems of food insecurity, the decrepit nature of buildings and equipment, the lack of adequate social infrastructure and the insufficient budget to reduce child and maternal mortality. Moreover, higher incomes lead to improved public-health infrastructure such as water and sanitation, along with better nutrition, better housing and the ability to pay for health care (Pritchett and Summers, 1996; Cutler, Deaton and Lleras-Muney, 2006).

The explanatory variables all have the expected signs and are statistically significant: the estimated coefficient on poverty shows that a 1 percentage-point reduction in the poverty rate decreases the child mortality rate by 1.05 points. This result is interpreted in accordance with the health economics literature that views poverty as a key determinant of mortality in general, particularly in developing countries. In fact, ill-health can be a catalyst for poverty spirals; and poverty, in turn, can create and perpetuate poor

\footnotetext{
6 To determine whether a structural equation in a system of linear simultaneous equations is identified, the following rule can be used: $\mathrm{G}=$ total number of endogenous variables in the model (i.e. in all equations that comprise the model); $\mathrm{K}=$ total number of variables (endogenous and exogenous) excluded in the equation being checked for identification. The order condition is as follows: if $K=G-1$, the equation is exactly identified; if $K>G-1$ the equation is over-identified; and if $K<G-1$ the equation is unidentified.

7 For details on the method used, see Bourbonnais (2002).
} 
health status. Poor households in developing countries are particularly vulnerable; and periods of ill-health can be viewed as an inherent part of the poverty experience. Serious illness forces people into poverty because they drop out of the labour market. Health is a crucially important economic asset for the poor, since their livelihoods depend on it. When a poor or socially vulnerable person becomes ill or injured, the entire household can become trapped in a downward spiral of lost income and high health-care costs. The poor are more vulnerable to this downward spiral because they are more vulnerable to disease and have more limited access to health care and social insurance. This means that a country's development depends on improving its population's health. Having a well-developed health-care system will thus help to improve labour productivity, which leads to higher wages and GDP and, hence, a lower poverty rate.

Table 3

Effects of health expenditures on child mortality (full sample)

\begin{tabular}{|c|c|c|c|}
\hline Variables & CHM Equation & GDPG Equation & HEXP Equation \\
\hline \multirow[t]{2}{*}{ GDPG } & -0.761 & -- & 0.361 \\
\hline & $(-3.7)^{\star \star \star}$ & -- & $(4.76)^{\star \star \star}$ \\
\hline \multirow[t]{2}{*}{ HEXP } & -0.171 & 0.472 & -- \\
\hline & $(-2.69)^{\star \star}$ & $(3.46)^{\star \star \star}$ & -- \\
\hline \multirow[t]{2}{*}{ POV } & 1.052 & -- & -- \\
\hline & $(4.46)^{\star \star}$ & -- & -- \\
\hline \multirow[t]{2}{*}{ Water } & -0.381 & -- & -- \\
\hline & $(-1.8)^{\star}$ & -- & -- \\
\hline \multirow[t]{2}{*}{ Life EXP } & -1.325 & -- & -- \\
\hline & $(2.76)^{\star \star \star}$ & -- & -- \\
\hline \multirow{2}{*}{ FemL } & -2.651 & -- & -- \\
\hline & $(4.18)^{\star \star \star}$ & -- & -- \\
\hline \multirow[t]{2}{*}{ URB } & -0.0364 & -- & -- \\
\hline & $(-3.3)^{\star \star}$ & -- & -- \\
\hline \multirow[t]{2}{*}{$\mathrm{CO}_{2}$} & 0.23 & -- & -- \\
\hline & $(4.32)^{\star \star}$ & -- & -- \\
\hline \multirow{2}{*}{ INQ } & -- & 0.724 & -- \\
\hline & -- & $(1.88)^{\star \star}$ & -- \\
\hline \multirow[t]{2}{*}{ INF } & -- & -0.266 & -- \\
\hline & -- & $(-1.72)^{\star}$ & -- \\
\hline \multirow[t]{2}{*}{ TRA } & -- & 0.364 & -- \\
\hline & -- & $(1.96)^{\star \star}$ & -- \\
\hline \multirow[t]{2}{*}{ FD } & -- & 0.455 & -- \\
\hline & -- & $(1.46)$ & -- \\
\hline \multirow[t]{2}{*}{$\mathbb{R}$} & -- & 1.452 & -- \\
\hline & -- & $(5.84)^{\star \star \star}$ & -- \\
\hline \multirow[t]{2}{*}{ LF } & -- & 0.768 & -- \\
\hline & -- & $(1.87)^{\star \star}$ & -- \\
\hline \multirow[t]{2}{*}{ TechProg } & -- & -- & 2.263 \\
\hline & -- & -- & $(1.89)^{\star \star}$ \\
\hline \multirow[t]{2}{*}{ DocDens } & -- & -- & 0.095 \\
\hline & -- & -- & $(4.49)^{\star \star}$ \\
\hline \multirow[t]{2}{*}{ PopStr } & -- & -- & 2.521 \\
\hline & -- & -- & $(2.05)^{\star \star \star}$ \\
\hline \multirow[t]{2}{*}{ INST } & -- & -- & 3.489 \\
\hline & -- & -- & $(5.24)^{\star \star \star}$ \\
\hline \multirow[t]{2}{*}{ Constant } & 5.974 & 7.562 & 3.887 \\
\hline & & $(6.75)^{\star *}$ & $(6.54)^{\star \star \star}$ \\
\hline Number of observations & 1767 & 1767 & 1767 \\
\hline $\mathrm{R}^{2}$ & 0.2 & 0.19 & 0.17 \\
\hline
\end{tabular}

Source: Prepared by the author.

Note: *significant at 10\%; ${ }^{\star \star}$ significant at $5 \%$; ${ }^{\star \star \star}$ significant at $1 \%$. 
The estimated coefficient on women's literacy rate appears to be significantly negative, suggesting that this is a true determinant of household health, with an impact equal to antenatal and postnatal care in developing countries. This result is consistent with the findings reported by Baldacci, Guin-Siu and de Mello (2003) and Schultz (1993), which showed that the mother's education level is an important determinant of health status both among children, and among the population at large. In developing countries, women play a more important role in family health and sanitation, quite apart from the fact that women's education is positively associated with child health and negatively associated with fertility rates.

In the case of urbanization, the coefficient shows that a 1 percentage point increase in the urban population will decrease the child mortality rate by 0.3 percentage points. In this context, Schultz (1993) showed that the child mortality rate is higher among rural, low-income, agricultural households than among their urban counterparts, partly because health care is typically more accessible in urban areas, and because the private cost of accessing health care (such as transport costs) may also be lower for urban households.

The environment variable, measured by $\mathrm{CO}_{2}$ emissions, displays a coefficient of 0.23 , significant at the $5 \%$ level, which means that a 1 percentage point increase in $\mathrm{CO}_{2}$ emissions is associated with a 0.23 percentage point increase in child mortality.

The second row of table 3 reports the results of the estimation of the economic-growth equation, showing a positive relationship between health expenditure and economic growth. The $\alpha_{5}$ value for this model, which measures the elasticity of economic growth with respect to health expenditure, appears statistically significant at the $5 \%$ level, which indicates that poor health is a major constraint on GDP growth. Better health increases labour productivity by reducing the number of days lost to sick leave, incapacity or disability. Moreover, healthier workers are physically and mentally more energetic and thus more effective in the labour market. Improving health and health indices in society will also encourage individuals to save more, given the reduction in mortality rates and longer life expectancy.

The income inequality variable, measured by the Gini coefficient, has the expected sign and is statistically significant: a 1 percentage point increase in income inequality reduces GDP growth by 0.7 percentage points child mortality rates. The specialist literature argues that, if income is redistributed from the rich, whose health is not greatly affected, to the poor, whose health is more responsive to income, the population's average health status will improve. Other things being equal, including average income, countries (or other population groups) that have a more equal income distribution will have a better average health status.

The results also show that the inflation variable has a significant and negative effect on poverty reduction processes. A $1 \%$ rise in the consumer price index is found to reduce economic growth by about 0.26 points, thus confirming inflation's negative role. This result is consistent with the theory put forward by Kpodar (2004), which views inflation as a constraint on growth because of its negative impact on the real value of assets and the purchasing power of household incomes.

The trade openness variable appears significantly positive, which supports the idea that a policy of abolishing trade barriers and promoting free capital movements enhances economic growth.

The third row of table 3 reports the estimation of the health-expenditure equation. As expected, the results show that health care is related positively and significantly to per capita GDP growth. This is consistent with theoretical predictions: if health expenditure can be regarded as an investment in human capital, which in turn is a key source of economic growth, an increase in health expenditure must ultimately lead to higher GDP and vice versa.

The coefficient on R\&D expenditure, representing technological progress, indicates that $R \& D$ is a key determinant of government health spending.

The coefficient on population structure is statistically significant at the $1 \%$ level, demonstrating that this variable is very strongly and positively correlated with health-care spending. This means that access to health care has a major positive impact on health spending. The physicians density variable 
is also statistically significant at the $5 \%$ level; so, a larger number of doctors per 1,000 population indicates more accessible health care and should correlate with a lower mortality rate.

\section{Calculating the total effect of health expenditure on child mortality rates}

As noted above, the main aim of this paper is to test whether health spending can reduce child mortality by positively influencing economic growth, and to evaluate the significance of any such effect. Mathematically, the direct and indirect effects of health expenditures on the under-five mortality rate can be expressed by calculating the mathematical derivative of $\mathrm{CHM}$ with respect to HEXP:

$$
\frac{\partial C H M}{\partial H E X P}=\gamma_{1} \frac{\partial G D P G}{\partial H E X P}+\gamma_{2}=\gamma_{1} * \alpha_{5}+\gamma_{2}
$$

Table 4 summarizes findings for the impact of health expenditures on child mortality: in terms of direct impact, a 1 percentage point increase in HEXP leads to a decrease in child mortality by $\gamma_{2}=0.17$ points. The indirect impact of HEXP on child mortality can be calculated as the product of the coefficient on economic growth in the HEXP equation with the coefficient on HEXP in the GDP growth equation $\left(\gamma_{1} \alpha_{5}=0.76 * 0.47=0.35\right)$. The total impact of HEXP on child mortality is equal to the sum of the direct and indirect effects (0.52), which indicates that a 1 percentage point increase in HEXP reduces the $\mathrm{CHM}$ rate by 0.52 percentage points.

Table 4

Total effect of health expenditures on child mortality

\begin{tabular}{lccc}
\hline & Direct impact of HEXP on CHM & $\begin{array}{c}\text { Indirect impact of HEXP on } \\
\text { CHM via economic growth }\end{array}$ & Total impact of HEXP on CHM \\
\hline Coefficient & $\gamma_{2}$ & $\gamma_{1}{ }^{*} \alpha_{5}$ & $\gamma_{1}{ }^{*} \alpha_{5}+\gamma_{2}$ \\
\hline Estimate & 0.17 & $0.76{ }^{*} 0.47=0.35$ & $0.76{ }^{*} 0.47+0.17=0.52$ \\
\hline
\end{tabular}

Source: Prepared by the author.

The results reported in table 4 clearly show that HEXP has a significant impact on child health status by improving economic growth and consequently children's living conditions. A $1 \%$ increase in HEXP can lead to an overall decrease in the child mortality rate of 0.52 percentage point split between a direct impact of 0.17 percentage points and an indirect impact of 0.35 points. This suggests that the indirect impact through economic growth is greater than the direct or traditional impact through access to health care to satisfy medical needs.

Lastly, it should be noted that the conclusions reached in this initial study do not seem to apply to all countries in the sample; and results may depend on the structural characteristics of each economy. The findings should be treated with great caution because the sample was heterogeneous, containing both developed and developing countries with different structures and economic strategies. Experience shows that higher government health spending is associated with lower child mortality rates, whereas lower government health spending is associated with higher rates.

\section{Sample decomposition and robustness analysis}

It is inappropriate to conduct a study on this subject with a sample of countries that do not have broadly similar characteristics, since it would not be possible to account for the specific nature of each country and might yield erroneous results that cannot be generalized. A sample separation might give more accurate results that reflect the heterogeneous nature of the groups studied. 
In the following paragraphs, the results are tested for robustness: first, by subdividing the full sample into four smaller ones. This means the results could be sensitive to sample choice, so the aim is to compare the four samples defined by income level. Following the World Bank classification, a database characterizing four samples can be drawn from countries around the world during 1995-2013: 20 low-income countries, 23 lower-middle-income countries, 25 upper-middle-income countries and 25 high-income countries. Although the economic history of each country is bound to be different, the countries in each grouping have similar economic and health statuses, as well as in political, regulatory and social or cultural circumstances. The aim here is to identify the policy implications that will be adopted by each group of countries. To that end, the same approach and empirical methodology will be used.

\section{(a) Robustness analysis}

The results of the regression models for the four country subgroupings are reported in tables 5 , 6, 7 and 8 , and should be interpreted cautiously.

Table 5

High-income countries: effects of health expenditures on child mortality

\begin{tabular}{|c|c|c|c|}
\hline Variables & $\begin{array}{c}\text { CHM } \\
\text { Equation }\end{array}$ & $\begin{array}{c}\text { GDPG } \\
\text { Equation }\end{array}$ & $\begin{array}{c}\text { HEXP } \\
\text { Equation }\end{array}$ \\
\hline \multirow[t]{2}{*}{ GDPG } & -1.214 & -- & 0.238 \\
\hline & $(-5.26)^{\star \star \star}$ & -- & $(3.07)^{\star \star \star}$ \\
\hline \multirow[t]{2}{*}{ HEXP } & -0.32 & 0.752 & -- \\
\hline & $(-4.28)^{\star \star}$ & $(2.93)^{\star \star}$ & -- \\
\hline \multirow[t]{2}{*}{ POV } & 2.84 & -- & -- \\
\hline & $(2.35)^{\star \star}$ & -- & -- \\
\hline \multirow[t]{2}{*}{ Water } & -0.649 & -- & -- \\
\hline & $(-2.36)^{\star \star}$ & -- & -- \\
\hline \multirow[t]{2}{*}{ Life EXP } & -2.025 & -- & -- \\
\hline & $(1.72)^{\star}$ & -- & -- \\
\hline \multirow[t]{2}{*}{ FemL } & -1.906 & -- & -- \\
\hline & $(3.12)^{\star \star}$ & -- & -- \\
\hline \multirow[t]{2}{*}{ URB } & -0.046 & -- & -- \\
\hline & $(-2.62)^{\star \star}$ & -- & -- \\
\hline \multirow[t]{2}{*}{$\mathrm{CO}_{2}$} & 0.235 & -- & -- \\
\hline & $(2.76)^{\star \star}$ & -- & -- \\
\hline \multirow[t]{2}{*}{ INQ } & -- & -0.102 & -- \\
\hline & -- & $(-2.67)^{\star \star}$ & -- \\
\hline \multirow[t]{2}{*}{ INF } & -- & -0.253 & -- \\
\hline & -- & $(-2.89)^{\star \star}$ & -- \\
\hline \multirow[t]{2}{*}{ TRA } & -- & 0.495 & -- \\
\hline & -- & $(2.04)^{\star \star}$ & -- \\
\hline \multirow[t]{2}{*}{ FD } & -- & 0.952 & -- \\
\hline & -- & $(3.26)^{\star *}$ & -- \\
\hline \multirow[t]{2}{*}{$\mathbb{R}$} & -- & 2.391 & -- \\
\hline & -- & $(2.643)^{\star \star \star}$ & -- \\
\hline \multirow[t]{2}{*}{ LF } & -- & 1.434 & -- \\
\hline & -- & $(2.12)^{\star \star}$ & -- \\
\hline \multirow[t]{2}{*}{ TechProg } & -- & -- & 3.522 \\
\hline & -- & -- & $(5.27)^{\star \star}$ \\
\hline \multirow[t]{2}{*}{ DocDens } & -- & -- & 0.205 \\
\hline & -- & -- & $(2.99)^{\star \star}$ \\
\hline \multirow[t]{2}{*}{ PopStr } & -- & -- & 2.523 \\
\hline & -- & -- & $(2.15)^{\star \star}$ \\
\hline \multirow[t]{2}{*}{ INST } & -- & -- & 0.712 \\
\hline & -- & -- & $(3.64)^{\star \star}$ \\
\hline
\end{tabular}


Table 5 (concluded)

\begin{tabular}{lccc}
\hline Variables & $\begin{array}{c}\text { CHM } \\
\text { Equation }\end{array}$ & $\begin{array}{c}\text { GDPG } \\
\text { Equation }\end{array}$ & $\begin{array}{c}\text { HEXP } \\
\text { Equation }\end{array}$ \\
\hline Constant & 10.157 & 8.445 & 6.367 \\
\cline { 2 - 4 } & $(4.33)^{\star \star \star}$ & $(4.751)^{\star \star \star}$ & $(4.37)^{\star \star}$ \\
\hline Number of observations & 475 & 475 & 475 \\
\hline $\mathrm{R}^{2}$ & 0.19 & 0.17 & 0.15 \\
\hline
\end{tabular}

Source: Prepared by the author.

Note: $\quad{ }^{*}$ significant at $10 \%$; ${ }^{\star \star}$ significant at $5 \%$; ${ }^{\star \star \star}$ significant at $1 \%$.

Table 6

Upper-middle income countries: effects of health expenditures on child mortality

\begin{tabular}{|c|c|c|c|}
\hline Variables & $\begin{array}{c}\text { CHM } \\
\text { Equation }\end{array}$ & $\begin{array}{c}\text { GDPG } \\
\text { Equation }\end{array}$ & $\begin{array}{c}\text { HEXP } \\
\text { Equation }\end{array}$ \\
\hline \multirow[t]{2}{*}{ GDPG } & -0.961 & -- & 0.56 \\
\hline & $(-1.99)^{\star \star}$ & -- & $(2.94)^{\star \star}$ \\
\hline \multirow[t]{2}{*}{ HEXP } & -0.242 & 2.16 & -- \\
\hline & $(-2.19)^{\star \star}$ & $(3.45)^{\star \star}$ & -- \\
\hline \multirow[t]{2}{*}{ POV } & 0.852 & -- & -- \\
\hline & $(2.47)^{\star \star}$ & -- & -- \\
\hline \multirow[t]{2}{*}{ Water } & -0.239 & -- & -- \\
\hline & $(-1.93)^{\star \star}$ & -- & -- \\
\hline \multirow[t]{2}{*}{ Life EXP } & -0.985 & -- & -- \\
\hline & $(2.76)^{\star \star}$ & -- & -- \\
\hline \multirow[t]{2}{*}{ FemL } & -1.854 & -- & -- \\
\hline & $(4.18)^{\star \star}$ & -- & -- \\
\hline \multirow[t]{2}{*}{ URB } & -0.043 & -- & -- \\
\hline & $(-2.41)^{\star \star}$ & -- & -- \\
\hline \multirow{2}{*}{$\mathrm{CO}_{2}$} & 0.213 & -- & -- \\
\hline & $(3.546)^{\star \star \star}$ & -- & -- \\
\hline \multirow[t]{2}{*}{ INQ } & -- & -0.223 & -- \\
\hline & -- & $(-1.18)$ & -- \\
\hline \multirow[t]{2}{*}{ INF } & -- & -0.262 & -- \\
\hline & -- & $(-2.52)^{\star \star}$ & -- \\
\hline \multirow[t]{2}{*}{ TRA } & -- & 0.341 & -- \\
\hline & -- & (1.48) & -- \\
\hline \multirow[t]{2}{*}{ FD } & -- & 1.895 & -- \\
\hline & -- & $(1.83)^{\star \star}$ & -- \\
\hline \multirow[t]{2}{*}{$\mathbb{R}$} & -- & 2.563 & -- \\
\hline & -- & $(4.26)^{\star \star}$ & -- \\
\hline \multirow[t]{2}{*}{ LF } & -- & 1.852 & -- \\
\hline & -- & (2.31) & -- \\
\hline \multirow[t]{2}{*}{ TechProg } & -- & -- & 2.403 \\
\hline & -- & -- & $(2.29)^{\star \star}$ \\
\hline \multirow[t]{2}{*}{ DocDens } & -- & -- & 0.133 \\
\hline & -- & -- & $(3.44)^{\star \star}$ \\
\hline \multirow[t]{2}{*}{ PopStr } & -- & -- & 2.954 \\
\hline & -- & -- & $(2.05)^{\star \star \star}$ \\
\hline \multirow[t]{2}{*}{ INST } & -- & -- & 0.624 \\
\hline & -- & -- & $(1.87)^{\star \star}$ \\
\hline \multirow[t]{2}{*}{ Constant } & 10.524 & 13.562 & 8.52 \\
\hline & $(7.69)^{\star \star \star}$ & $(3.12)^{\star \star}$ & $(5.2)^{\star \star \star}$ \\
\hline Number of observations & 720 & 720 & 720 \\
\hline $\mathrm{R}^{2}$ & 0.2 & 0.19 & 0.16 \\
\hline
\end{tabular}

Source: Prepared by the author.

Note: ${ }^{*}$ significant at $10 \%$; ${ }^{\star *}$ significant at $5 \%$; ${ }^{* \star}$ significant at $1 \%$. 
Table 7

Effects of health expenditures on child mortality (lower-middle-income countries)

\begin{tabular}{|c|c|c|c|}
\hline Variables & $\begin{array}{c}\mathrm{CHM} \\
\text { Equation }\end{array}$ & $\begin{array}{c}\text { GDPG } \\
\text { Equation }\end{array}$ & $\begin{array}{c}\text { HEXP } \\
\text { Equation }\end{array}$ \\
\hline \multirow[t]{2}{*}{ GDPG } & -0.76 & -- & 0.275 \\
\hline & $(-3.73)^{\star \star \star}$ & -- & $(2.16)^{\star *}$ \\
\hline \multirow[t]{2}{*}{ HEXP } & -0.318 & 0.325 & -- \\
\hline & $(-1.38)$ & $(1.76)^{\star}$ & -- \\
\hline \multirow[t]{2}{*}{ POV } & 2.62 & -- & -- \\
\hline & $(2.91)^{\star \star}$ & -- & -- \\
\hline \multirow[t]{2}{*}{ Water } & -0.381 & -- & -- \\
\hline & $(-3.74)^{\star \star}$ & -- & -- \\
\hline \multirow[t]{2}{*}{ Life EXP } & -2.82 & -- & -- \\
\hline & $(-2.77)^{\star \star}$ & -- & -- \\
\hline \multirow[t]{2}{*}{ FemL } & -2.71 & -- & -- \\
\hline & $(3.43)^{\star \star \star}$ & -- & -- \\
\hline \multirow[t]{2}{*}{ URB } & -0.24 & -- & -- \\
\hline & $(-3.56)^{\star \star \star}$ & -- & -- \\
\hline \multirow[t]{2}{*}{$\mathrm{CO}_{2}$} & 0.238 & -- & -- \\
\hline & $(5.645)^{\star \star \star}$ & -- & -- \\
\hline \multirow[t]{2}{*}{ INQ } & -- & 0.176 & -- \\
\hline & -- & (1.38) & -- \\
\hline \multirow[t]{2}{*}{ INF } & -- & -0.254 & -- \\
\hline & -- & $(-2.81)^{\star \star}$ & -- \\
\hline \multirow[t]{2}{*}{ TRA } & -- & 0.351 & -- \\
\hline & -- & $(1.97)^{\star \star}$ & -- \\
\hline \multirow[t]{2}{*}{ FD } & -- & 0.845 & -- \\
\hline & -- & $(1.76)^{\star \star}$ & -- \\
\hline \multirow[t]{2}{*}{ IR } & -- & 1.543 & -- \\
\hline & -- & $(1.69)^{\star}$ & -- \\
\hline \multirow[t]{2}{*}{ LF } & -- & 1.212 & -- \\
\hline & -- & $(2.11)^{\star \star}$ & -- \\
\hline \multirow[t]{2}{*}{ TechProg } & -- & -- & 1.263 \\
\hline & -- & -- & $(2.66)^{\star \star}$ \\
\hline \multirow[t]{2}{*}{ DocDens } & -- & -- & 0.093 \\
\hline & -- & -- & $(3.17)^{\star \star}$ \\
\hline \multirow[t]{2}{*}{ PopStr } & -- & -- & 2.215 \\
\hline & -- & -- & $(1.97)^{\star \star \star}$ \\
\hline \multirow[t]{2}{*}{ INST } & -- & -- & 0.649 \\
\hline & -- & -- & $(1.66)^{\star}$ \\
\hline \multirow[t]{2}{*}{ Constant } & 5.974 & 7.562 & 11.415 \\
\hline & $(5.82)^{\star \star \star}$ & $(4.95)^{\star \star}$ & $(3.51)^{\star \star \star}$ \\
\hline Number of observations & 552 & 552 & 552 \\
\hline $\mathrm{R}^{2}$ & 0.19 & 0.18 & 0.15 \\
\hline
\end{tabular}

Source: Prepared by the author.

Note: ${ }^{*}$ significant at $10 \%$; ${ }^{* \star}$ significant at $5 \%$; ${ }^{* \star}$ significant at $1 \%$. 
Table 8

Effects of health expenditures on child mortality (low-income countries)

\begin{tabular}{|c|c|c|c|}
\hline Variables & $\begin{array}{c}\text { CHM } \\
\text { Equation }\end{array}$ & $\begin{array}{l}\text { GDPG } \\
\text { Equation }\end{array}$ & $\begin{array}{c}\text { HEXP } \\
\text { Equation }\end{array}$ \\
\hline \multirow[t]{2}{*}{ GDPG } & -0.082 & -- & 0.344 \\
\hline & $(-3.7)^{\star \star \star}$ & -- & $(2.79)^{\star \star}$ \\
\hline \multirow[t]{2}{*}{ HEXP } & 0.083 & 0.288 & -- \\
\hline & $(1.44)$ & $(1.49)$ & -- \\
\hline \multirow[t]{2}{*}{ POV } & 0.76 & -- & -- \\
\hline & $(2.47)^{\star \star}$ & -- & -- \\
\hline \multirow[t]{2}{*}{ Water } & -0.204 & -- & -- \\
\hline & $(-1.84)^{\star \star}$ & -- & -- \\
\hline \multirow[t]{2}{*}{ Life EXP } & -1.65 & -- & -- \\
\hline & $(2.76)^{\star \star \star}$ & -- & -- \\
\hline \multirow[t]{2}{*}{ FemL } & -2.651 & -- & -- \\
\hline & $(-3.18)^{*}$ & -- & -- \\
\hline \multirow[t]{2}{*}{ URB } & -0.436 & -- & -- \\
\hline & $(-2.82)^{\star \star}$ & -- & -- \\
\hline \multirow[t]{2}{*}{$\mathrm{CO}_{2}$} & 0.227 & -- & -- \\
\hline & $(3.471)^{\star \star}$ & -- & -- \\
\hline \multirow[t]{2}{*}{ INQ } & -- & 0.072 & -- \\
\hline & -- & $(1.88)^{\star \star}$ & -- \\
\hline \multirow[t]{2}{*}{ INF } & -- & -0.262 & -- \\
\hline & -- & $(-1.72)^{\star}$ & -- \\
\hline \multirow[t]{2}{*}{ TRA } & -- & 0.364 & -- \\
\hline & -- & $(1.26)$ & -- \\
\hline \multirow[t]{2}{*}{ FD } & -- & 0.865 & -- \\
\hline & -- & $(1.76)^{\star \star}$ & -- \\
\hline \multirow[t]{2}{*}{ IR } & -- & 1.485 & -- \\
\hline & -- & $(1.46)$ & -- \\
\hline \multirow[t]{2}{*}{$\mathrm{LF}$} & -- & 1.35 & -- \\
\hline & -- & $(1.71)^{\star}$ & -- \\
\hline \multirow[t]{2}{*}{ TechProg } & -- & -- & 0.26 \\
\hline & -- & -- & $(1.88)^{\star \star}$ \\
\hline \multirow[t]{2}{*}{ DocDens } & -- & -- & 0.113 \\
\hline & -- & -- & $(4.49)^{\star \star}$ \\
\hline \multirow[t]{2}{*}{ PopStr } & -- & -- & 2.562 \\
\hline & -- & -- & $(2.77)^{\star \star}$ \\
\hline \multirow[t]{2}{*}{ INST } & -- & -- & 0.89 \\
\hline & -- & -- & $(1.26)$ \\
\hline \multirow[t]{2}{*}{ Constant } & 4.547 & 6.541 & 3.887 \\
\hline & $(9.38)^{\star \star \star}$ & $(7.67)^{\star \star}$ & $(6.54)^{\star \star \star}$ \\
\hline Number of observations & 480 & 480 & 480 \\
\hline $\mathrm{R}^{2}$ & 0.19 & 0.17 & 0.15 \\
\hline
\end{tabular}

Source: Prepared by the author.

Note: * significant at $10 \%$; ${ }^{\star \star}$ significant at $5 \%$; ${ }^{\star \star \star}$ significant at $1 \%$.

The results show that the explanatory variables vary according to the sample considered. Interestingly, the simple regression holds true for the models using the all-countries sample and for the upper-middle- and high-income groupings. Nonetheless, for low-income and lower-middleincome countries, the model is unable to explain the relationship between child mortality and health expenditure. In other words, government health spending has a positive and significant effect in terms of reducing mortality rates for upper-middle- and high-income countries; but its effects are not statistically significant for low- and lower-middle-income countries. This result is logical because, 
according to the specialist literature, health expenditure has a positive effect on child mortality when it exceeds a certain threshold, which is generally assumed to have been reached in emerging and developed countries. In contrast, in lower- and lower- middle-income countries where health systems are still unable to offer medical services to all segments of society, spending may not have beneficial effects in terms of reducing mortality. This may also explain the poor health infrastructure and workforce health across these groups, as limited resources are allocated to the provision and maintenance of health-related infrastructure. It may also be explained by the fact that in upper-middleand high-income countries, higher income promotes accessibility to improved health facilities, better nutrition, sanitation, education and medical care. In contrast, children born in low-income countries are more likely to experience health problems from birth and accumulate health risks as they grow older. Factors such as education, technological change, income and cultural differences can be identified as the key drivers of health outcomes, rather than health spending. Furthermore, in less developed countries where resources are scarcer, health expenditure generally has a lower priority in government budgets.

Individuals belonging to lower socioeconomic groups are also less likely to access health care: an increase in user fees in public clinics will affect the poor more than the better-off. This result is consistent with other studies that found no significant relationship between access to health care and child mortality, but which show that children born into low-income households are more likely to suffer developmental and health problems from birth and to accumulate health risks as they grow older (Filmer and Pritchett, 1999; Thornton, 2002; Roberts, 2003). Still others, such as Viegi and Baldacci (2002), found that their results depend on the dataset and/or estimation methods used, or that the healthexpenditure contribution to health status is either small or statistically insignificant (Filmer, Hammer and Pritchett, 1998).

The absence of significant effects from health expenditures in these less developed countries may be explained by the rising costs of medical technology, while another reason for the difference between developed and developing countries may be inefficiency in health care spending. Moreover, corruption is more common in these less developed countries, and the priority given to health spending is fairly low. At the micro level, households in developing countries are often locked into a poverty trap, which contributes significantly to their poor health status. Institutional variables that reflect the quality of governance, such as property rights, administrative procedures and the functioning of the public sector, may also explain differences in access to medical services. Thus, high levels of institutional quality are synonymous with equal access to services. This means that equity considerations need to be included in public-health policies, which are currently relatively unfavourable to the poor. Thus, the model's inability to explain the relationship between health-care spending and child mortality suggests that government spending is neither efficient nor effective. Intuitively, the institutional context seems at least as influential as the amount of health spending and is likely to be a decisive factor in the relationship between health expenditure and child mortality. Middle- and high-income countries that have reduced their mortality rates have adopted policies based on fulfilling traditional prerequisites (limits on public deficits, health infrastructure, female literacy, etc.), and especially on the conditions for institutional good governance.

\section{Private and/or public expenditure on health and child mortality}

This study's findings show that an accurate assessment of the role of health expenditure on child mortality rates requires this expenditure to be broken down into its private and public components. This section aims to do this and also test their effects on the four country subgroups. The results, set out in table 9 and obtained using the same model, same techniques and same period, reveal a strong 
negative relation between public health expenditure and child mortality rates in low-, lower-middle- and upper-middle-income countries, in which a $1 \%$ increase in this expenditure would, on average, reduce child mortality by 0.2 percentage points. By contrast, the study found no significant relationship between public expenditure on health and child mortality rates in high-income countries. This may be explained by the fact that in less developed countries, public expenditure on health is used to provide and develop health-care facilities and improve the functioning of the health system.

Table 9

Summary of the effects of private and public health expenditure on child mortality rates

\begin{tabular}{lcc}
\hline & Public expenditure & Private expenditure \\
\hline \multirow{2}{*}{ Low-income countries } & 0.002 & 1.26 \\
\cline { 2 - 3 } & $(3.45)^{\star \star}$ & $(0.98)$ \\
\hline Lower-middle-income countries & 0.002 & 0.03 \\
\cline { 2 - 3 } & $(2.87)^{\star \star}$ & $(1.42)$ \\
\hline Upper-middle-income countries & 0.001 & 0.002 \\
\hline High-income countries & $(1.95)^{\star \star}$ & $(2.67)^{\star \star \star}$ \\
\cline { 2 - 3 } & 0.011 & 0.015 \\
\hline
\end{tabular}

Source: Prepared by the author.

Note: * significant at $10 \%$; ${ }^{*}$ significant at $5 \%$; ${ }^{* \star}$ significant at $1 \%$.

In terms of the impact of private expenditure, the study revealed a negative and significant relationship between private expenditure and child mortality rates in upper-middle- and high-income countries, but no evidence of such a relationship in the low- and lower-middle-income groups. The extent to which private health-care spending affects the health system seems to depend on the effectiveness of policies and institutions. This is consistent with the results reported by Burnside and Dollar (2004) that there is no significant relationship between private health-care expenditure and changes in child mortality in less developed countries.

Lastly, it can be concluded from this study that public expenditure on health is the main channel through which child health is improved in countries that are in the early stages of development; but as a country attains higher levels of development, private expenditure on health takes over as the primary channel affecting child mortality rates. Gupta, Verhoeven and Tiongson (2001) use evidence from 50 countries to show that public spending on health care is more important for the health of the poor in low-income countries than in high-income ones, which suggests that the returns to health spending are higher in the former countries than in the latter.

\section{Conclusion and policy implications}

This study set out to test the impact of health-care expenditure on child mortality rates. Although the literature on this subject is vast, theoretical and empirical developments lead to mixed conclusions, this paper sought to clarify the relationship by examining the aforementioned interaction, focusing on the role played by economic growth for 93 developed and developing countries using a simultaneousequations model with data spanning 1995-2013. The hypothesis of the research was that there would be a negative correlation between health expenditure and child mortality, such that an increase in spending would cut under-five mortality rates. Results show that higher spending was found to be positive and significant only in upper-middle- and high-income countries but not for low- and lower-middle-income ones. The insignificance of health-care spending in the latter country groupings may indicate that 
resources are not being allocated effectively towards health spending. The findings also confirm the importance of GDP growth in explaining both health expenditure and child mortality. They also show that in less developed countries, public expenditure on health has a greater effect on mortality rates than private health expenditure, while at high development levels private expenditure has a positive impact on child health status.

The empirical results obtained in the present study, in conjunction with the ensuing discussion, provide several important lessons and policy implications for those involved in designing health programmes to improve child mortality rates, in particular, and health status in general. Governments should increase the amount of resources allocated to health-service delivery. In addition, establishing effective publicprivate partnerships to develop the health sector could go a long way towards improving the population's health status. To reduce child mortality rates, economies need to undertake a number of reforms. Although government spending can contribute to reducing child mortality in the wealthiest countries, health expenditure should not be confined to government spending alone, since private spending and external sources can also improve health-care access to satisfy medical needs. Countries should also increase their spending on education because female literacy can be an important determinant of their children's health status, and that of the population at large. In short, child mortality can be reduced by strengthening national health systems, expanding immunization programmes, enhancing child growth monitoring, ensuring the survival and improved health of mothers, supporting better mother and child nutrition, and investing in better reproductive health and in infrastructure.

\section{Bibliography}

Baldacci, E., M. T. Guin-Siu and L. de Mello (2003), "More on the effectiveness of public spending on health care and education: a covariance structure model", Journal of International Development, vol. 15, No. 6, Wiley.

Baldacci, E. and others (2004), "Social spending, human capital, and growth in developing countries: implications for achieving the MDGs", IMF Working Paper, No. 04/217, Washington, D.C., International Monetary Fund (IMF).

Barro, R. (1996), "Determinants of economic growth: a cross-country empirical study", NBER Working Paper, No. 5968, Cambridge, Massachusetts, National Bureau of Economic Research (NBER).

Berger, M. C. and J. Messer (2002), "Public financing of health expenditures, insurance, and health outcomes", Applied Economics, vol. 34, No. 17, Taylor \& Francis.

Black, R. and others (2010), "Global, regional, and national causes of infant mortality in 2008: a systematic analysis", The Lancet, vol. 375, No. 9730.

Bokhari, F., Y. Gai and P. Gottret (2007), "Government health expenditures and health outcomes", Health Economics, vol. 16, No. 3, Wiley.

Bourbonnais, R. (2002), Économétrie, Paris, Dunod.

Burnside, C. and D. Dollar (2004), "Aid, policies, and growth: revisiting the evidence", Policy Research Working Paper, No. WPS 3251, Washington, D.C., World Bank.

Cutler, D., A. Deaton and A. Lleras-Muney (2006), "The determinants of mortality", Journal of Economic Perspectives, vol. 20, No. 3, Nashville, Tennessee, American Economic Association.

Dhrifi, A. (2015), "Financial development and the 'growth-inequality-poverty' triangle", Journal of the Knowledge Economy, vol. 6, No. 4, Springer.

(2014), "Agricultural productivity and poverty alleviation: what role for technological innovation", Journal of Economics and Social Studies, vol. 4, No. 1.

Filmer, D., J. S. Hammer and L. H. Pritchett (1998), "Health policy in poor countries: weak links in the chain", Policy Research Working Paper, No. 1874, Washington, D.C., World Bank.

Filmer, D. and L. Pritchett (1999), "The impact of public spending on health: does money matter?", Social Science \& Medicine, vol. 49, No. 10, Amsterdam, Elsevier.

(1997), "Infant mortality and public spending on health: how much does money matter?", Policy Research Working Paper, No. 1864, Washington, D.C., World Bank. 
Gupta, S. and A. Baghel (1999), "Infant mortality in the Indian slums: case studies of Calcutta metropolis and Raipur City", Population, Space and Place, vol. 5, No. 5, Wiley.

Gupta, S., M. Verhoeven and E. Tiongson (2002), "The effectiveness of government spending on education and health care in developing and transition economies", European Journal of Political Economy, vol. 18, No. 4, Amsterdam, Elsevier.

- (2001), "Public spending on health care and the poor", IMF Working Paper, No. WP/01/127, Washington, D.C., International Monetary Fund (IMF).

Harttgen, K. and M. Misselhorn (2006), "A Multilevel Approach to Explain Infant mortality and Undernutrition in South Asia and Sub-Saharan Africa" [online] https://www.econstor.eu/bitstream/10419/19847/1/Misselhorn.pdf.

Inter-Agency Group for Child Mortality Estimation (2015), Levels \& Trends in Child Mortality: Report 2015, New York, United Nations Children's Fund (UNICEF).

Khaleghian, P. and M. Das Gupta (2005), "Public management and the essential public health functions", World Development, vol. 33, No. 7, Amsterdam, Elsevier.

Kpodar, K. R. (2004), "Le développement financier et la problématique de réduction de la pauvreté", Working Paper, No. 200408, Clermont-Ferrand, Centre d'Études et de Recherche sur le Développement International (CERDI).

Musgrove, P. (1996), "Public and private roles in health: theory and financing patterns", HNP Discussion Paper, No. 339, Washington, D.C., World Bank.

Nixon, J. and P. Ulmann (2006), "The relationship between health care expenditure and health outcomes", European Journal of Health Economics, vol. 7, No. 1, Springer.

Nolte, E. and M. Mckee (2004), Does Health Care Save Lives? Avoidable Mortality Revisited, London, The Nuffield Trust.

Odhiambo, N. M. (2009), "Finance-growth-poverty nexus in South Africa: a dynamic causality linkage", The Journal of Socio-Economics, vol. 38, No. 2, Amsterdam, Elsevier.

Pritchett, L. and L. H. Summers (1996), "Wealthier is healthier", The Journal of Human Resources, vol. 31, No. 4, Madison, University of Wisconsin Press.

Ravallion, M. (1997), "Can high-inequality developing countries escape absolute poverty?", Economics Letters, vol. 56, No. 1, Amsterdam, Elsevier.

Roberts, R. (2003), "Poverty reduction outcomes in education and health public expenditure and aid", Working Paper, No. 210, London, Overseas Development Institute.

Roberts, B. W. and T. Bogg (2004), "A longitudinal study of the relationships between conscientiousness and the social-environmental factors and substance-use behaviors that influence health", Journal of Personality, vol. 72, No. 2, Wiley.

Schultz, T. P. (1993), "Studying the impact of household economic and community variables on infant mortality", Population and Development Review, vol. 10, New York, Population Council.

Scheffler, R. and others (2009), "Estimates of sub-Saharan Africa health care professional shortages in 2015", Health Affairs, vol. 28, No. 5.

Thornton, J. (2002), "Estimating a health production function for the US: some new evidence", Applied Economics, vol. 34, No. 1, Taylor \& Francis.

Viegi, G. and S. Baldacci (2002), "Epidemiological studies of chronic respiratory conditions in relation to urban air pollution in adults", The Impact of Air Pollution on Respiratory Health, G. d'Amato and S. T. Holgate (eds.), European Respiratory Society.

Wagstaff, A. (2002), "Poverty and health sector inequalities", Bulletin of the World Health Organization, vol. 80, No. 2, Geneva.

Wagstaff, A., E. van Doorslaer and N. Watanabe (2003), "On decomposing the causes of health sector inequalities, with an application to malnutrition inequalities in Vietnam", Journal of Econometrics, vol. 112, No. 1, Amsterdam, Elsevier.

Wang, Y. and J. Q. Wang (2002), "A comparison of international references for the assessment of child and adolescent overweight and obesity in different populations", European Journal of Clinical Nutrition, vol. 56, No. 10, London, Springer Nature.

WHO (World Health Organization) (2014), Consultation on Improving Measurement of the Quality of Maternal, Newborn and Child Care in Health Facilities, Geneva. (2001), "Global Public Goods for Health: New Strategies for the 21st Century", Commission on Macroeconomics and Health [online] http://www.cid.harvard.edu.

Zakir, M. and P. V. Wunnava (1997), "Factors affecting infant mortality rates: evidence from cross-sectional data", Applied Economics Letters, vol. 6, No. 5, Taylor \& Francis. 
